УДК 549.283:553.07(571.52)

ОЦЕНКА РЕСУРСОВ ТЕХНОГЕННЫХ ОБРАЗОВАНИЙ
ОТРАБОТАННЫХ РОССЫПЕЙ ЗОЛОТА КАРА-ХЕМ, ПРОЕЗДНОЙ (ТУВА)

Прудников С.Г., Хертек Ч.М.

Тувинский институт комплексного освоения природных ресурсов СО РАН, Кызыл, e-mail:prudnikov_s@inbox.ru

\begin{abstract}
Выполнена оценка ресурсного потенциала техногенных отложений (отвалов перемытых песков), сформировавшихся в результате отработки россыпей золота Кара-Хем и Проездной Тапса-Каахемского золотоносного района (Тува). В долине р. Кара-Хем установлена промышленная техногенная россыпь золота на участке мускульной отработки и две непромышленные россыпи на участках дражной и гидравлической отработок. Прогнозные ресурсы золота в промышленной техногенной россыпи оцениваются в 140,8 кг при среднем содержании золота 376 мг/м³. Прогнозные ресурсы золота на участках дражной и гидравлической отработок оцениваются авторами в 65,9 кг при среднем содержании 59 и 139 мг/м³. В техногенной россыпи Кара-Хем преобладает крупное $(78,4$ вес/\%), слабоокатанное $(94,5 \%)$ золото, комковатой $(80,7 \%)$ и уплощенной $(17,8 \%)$ формы, что гарантирует высокую извлекаемость при ее отработке. Пробность золота $860 \%$. Оценка россыпей проводилась с помощью бульдозерных траншей, из которых отбирались валовые посекционные пробы, промываемые на промприборе. В долине р. Проездной установлена непромышленная техногенная россыпь золота на участках мускульной и гидравлической отработки. Прогнозные ресурсы золота техногенных отложений оцениваются авторами в 11,5 кг. при среднем содержании 87 мг/м³. Главным видом опробования гале-эфельных отвалов россыпи Проездной являются среднеобъемные рядовые про-

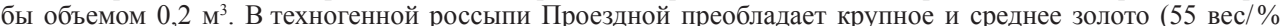
и 25,8 вес $/ \%)$, слабоокатанное, комковатой формы. Пробность золота $902 \%$. Техногенные отложения отработанных россыпей Кара-Хем и Проездной обладают высоким потенциалом для их повторной отработки небольшими золотодобывающими предприятиями.
\end{abstract}

Ключевые слова: техногенные отложения, отвалы, техногенные россыпи, ресурсы золота, россыпи, пробность золота, Тува

\title{
ESTIMATION OF RESOURCES OF TECHNOGENIC FORMATIONS OF PROCESSED GOLD PLACER KARA-HEM, THE PROEZDNOI (TUVA)
}

\author{
Prudnikov S.G., Khertek Ch.M.
}

Tuvinian Institute for Exploration of Natural Resources of Siberian Branch of the RAS, Kyzyl, e-mail:prudnikov_s@inbox.ru

The paper considers the evaluation of resource potential for technogenic deposits (dump areas of washed sands) formed as a result of the Kara-Khem gold mining placer as well as the Proezdnoi Tapsa-Kaakhem gold-bearing area (Tuva). The industrial technogenic gold placer within muscular work area and two non-industrial placers within dredging and hydraulic work areas are discovered by us in the valley of the Kara-Khem river. Gold reserves in industrial technogenic placers are estimated at $140.8 \mathrm{~kg}$ with an average gold grade of $376 \mathrm{mg} / \mathrm{m}^{3}$. Undiscovered gold resources within dredging and hydraulic work areas are estimated by the authors at $65.9 \mathrm{~kg}$. with an average gold grade of 59 and $139 \mathrm{mg} / \mathrm{m}^{3}$. The Kara-Khem tecnogenic placer is dominated by gold characterized as coarse $(78.4 \mathrm{wt} / \%)$, lightly rolled $(94.5 \%)$, lumpy $(80.7 \%)$ and flattened $(17.8 \%)$ that guarantees high recoverability in mining. Gold fineness is $860 \%$. Evaluation of the placers is carried out using bulldozer trenches from which wholesale sectional samples washed on the industrial instrument. The industrial technogenic gold placer within muscular and hydraulic work areas is discovered by us in the valley of the Proezdnoi river. Undiscovered gold resources of technogenic deposits are estimated by the authors at $11.5 \mathrm{~kg}$ with an average gold grade of $87 \mathrm{mg} / \mathrm{m}^{3}$ The main sampling survey of gale-lixiviation dumps of the Proezdnoi placer is medium-volume standard samples with $0.2 \mathrm{~m}^{3}$. The Proezdnoi placer is dominated by coarse and mid-size gold $(55 \mathrm{wt} / \%$ and $25.8 \mathrm{wt} / \%)$, slightly rolled and lumpy. Gold fineness is $902 \%$. The technogenic deposits of the Kara-Khem and the Proezdnoi mining placers have a high potential for their re-mining by small gold mining companies.

Keywords: technogenic deposits, dumps, technogenic placers, gold resources, placers, gold fineness, Tuva

Знаменитые тувинские россыпи золота длительное время определяли экономику Республики Тыва [1]. За период с 1848 по 2018 г. из этих россыпей было добыто около 50 т золота. В разные этапы освоения россыпей на местах добычи были складированы значительные по объему отвалы перемытых песков, которые можно подразделить на отвалы мускульной, дражной и гидравлической отработки. В связи с ис- тощением запасов россыпных месторождений в регионе возникла необходимость изучения ресурсного потенциала этих техногенных образований для их повторной эксплуатации.

Цель исследования: изучение ресурсного потенциала техногенных образований отработанных россыпей золота Кара-Хем и Проездной Тапса-Каахемского золотоносного района. 


\section{Материалы и методы исследования}

В ходе полевых экспедиционных исследований 2017-2018 гг. были проведены работы по выявлению, систематизации, опытному опробованию и переоценке техногенных образований отработанных россыпей Проездной, Кара-Хем для оценки возможности повторной отработки галеэфельного комплекса россыпных месторождений, отрабатываемых старателями в разные годы. Изучение гранулометрических и морфометрических особенностей золота и попутных компонентов техногенных россыпей, благоприятных для повторной их отработки с применением традиционных промывочных приборов, диагностика и анализ золота проводились в лаборатории геодинамики, магматизма и рудообразования ФГБУН ТувИКОПР СО РАН.

\section{Результаты исследования и их обсуждение}

Тапса-Каахемский золотоносный район выделяется в пределах Каахемской зоны смятия, являющейся важной 30лотоносной структурой Тувы [1, 2]. Он объединяет россыпные месторождения золота Иткин, Кара-Хем, Тапса, О-Хем, Проездной в бассейне р. Тапсы, россыпные месторождения р. Копто и ее притоков, а также месторождение рудного золота Проездной. В общем балансе россыпной золотоносности Тувы они включают 7,1\% россыпного золота. Россыпные месторождения эксплуатировались в течение длительного периода с 1904 г. вплоть до настоящего времени (табл. 1). существовало 3 прииска, на нижнем из них в 1912-1918 гг. работала драга, а на остальных отработка велась мускульным способом. Всего за период с 1905 по 1994 г. на месторождении добыто около 2100 кг золота. Применялся мускульный, гидравлический и раздельный гидромеханический способы отработки. Отрезок долины р. Кара-Хем протяженностью 6,5 км, на котором обрабатывалась россыпь, имеет в настоящее время ярко выраженный техногенный ландшафт. Особенности ландшафта и характер слагающих его техногенных образований позволили разделить отработанную россыпь на участки в зависимости от применявшихся способов отработки (дражной, мускульной и гидравлической отработки), а затем оценить каждый из них в отдельности (рис. 1). Оценка произведена по данным «Поисково-оценочных работ на россыпное золото в техногенных отложениях долины р. КараХем» - отчет артели старателей «Тыва» по работам 1997-1999, Горшков В.С.

Участок дражной отработки протяженностью 1,3 км выделен вниз от впадения руч. Горелого (рис. 1). Техногенный рельеф дражных отвалов можно охарактеризовать как «холмисто-бугристый» беспорядочный, обусловленный непрерывным чередованием мелких неправильных форм с вертикальным размахом до 3 м, на фоне которых выделяются отдельные более крупные «холмы» высотой до 5-7 м. На буграх наблюдаются высыпки гравийногалечного материала с мелкими валунами, в котором много плитчатого щебня пород коренного ложа (результат задирки плотика). Разрез участка дражной отработки был

Параметры отработанных россыпей Тапса-Каахемского района

Таблица 1

\begin{tabular}{|c|c|c|c|c|c|c|}
\hline \multirow[t]{2}{*}{ Россыпь } & \multirow[t]{2}{*}{ Длина, км } & \multirow[t]{2}{*}{ Ширина, м } & \multicolumn{2}{|c|}{ Мощность, м } & \multirow[t]{2}{*}{ 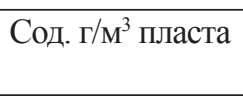 } & \multirow[t]{2}{*}{ Добыто золота, кг } \\
\hline & & & торфов & пласта & & \\
\hline Кара-Хем (Тапса) & 6,1 & $20-200$ & $4-6$ & $1-2$ & $2,5-4$ & 2100 \\
\hline Копто & 3,5 & 95 & $5-6$ & $1-1,6$ & 2 & 338 \\
\hline М. Проездной & 1.0 & $15-25$ & 5,0 & 1.0 & 2.8 & 372 \\
\hline
\end{tabular}

Техногенная россыпь Кара-Хем. КараХемское месторождение россыпного золота известно с 1903 г. [3]. Преобладающее большинство россыпей относится к долинным пойменным, значительно меньше доля долинных россыпей погребенного вреза, террасовых, террасоувальных, ложковых и техногенных россыпей. Эксплуатация месторождения начата в 1905 г. До 1918 г. изучен траншеей 130. Дражные отвалы на две трети состоят из гале-эфельных образований, представленных валунно-гравийно-галечным материалом желтовато-серого цвета с примесью плитчатого щебня и дресвы, состоящих из пород плотика. Обломочный материал составляет 80-90\%, заполнитель - 10-20\%, представлен песком, суглинком. Под гале-эфельными об- 
разованиями лежат эфеля, представленные серым песчано-гравийным материалом с линзовидно-слоистой текстурой. Приплотиковый слой отвалов обогащен валунами (20-40\%). Средняя мощность техногенных отложений - 4,0 м. Среднее содержание 3олота по траншее 130 в целом, включая при-

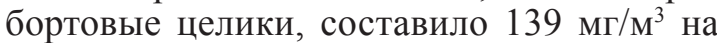
массу, при минимально промышленном содержании 210 мг/м³ (на блок), таким образом, на дражном полигоне можно ожидать забалансовые запасы золота. лены здесь гале-эфельными образованиями, перебуторенными в процессе добычных работ и явно перемытыми впоследствии рекой. Они представляют собой валунно-галечный материал с песчаным и супесным цементом. Обломочный материал составляет 60-70\% объема породы, причем на долю валунов приходится 15-25\%. Количество и размер валунов возрастает сверху вниз по разрезу, и наиболее крупные из них (до 1,5 м) лежат на плотике, что вызвано, видимо, перемывом отложений. Мощность слоя от 0,5 до 3 м.

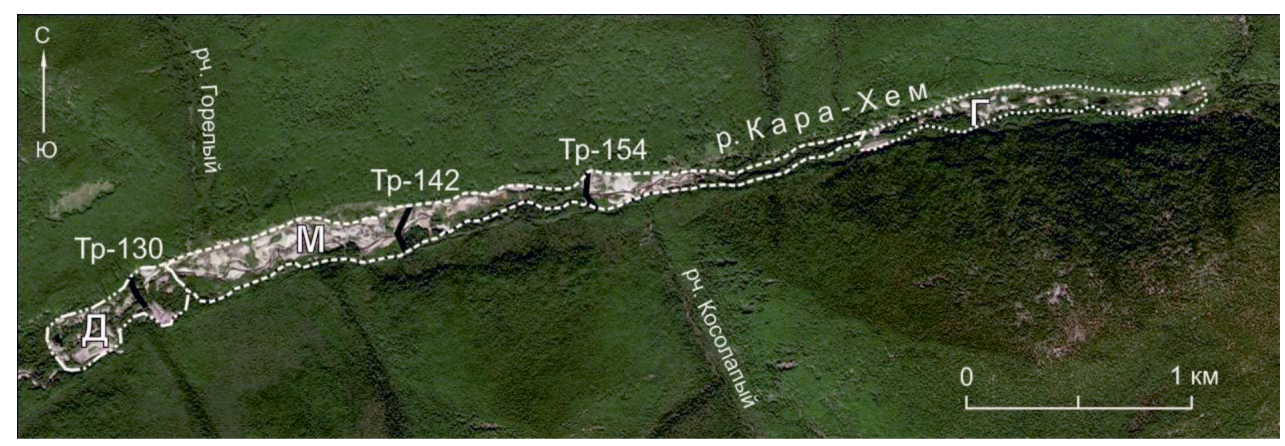

Рис. 1. Техногенная россыпь Кара-Хем: Д-участок дражной отработки, М - участок мускульной отработки, Г-участок гидравлической отработки россыпи. Тр-130-разведочные траншеи и их номера

Участок мускульной отработки примыкает к верхнему окончанию дражного полигона и прослеживается на 2,7 км вверх до устья руч. Кедрового. Техногенный рельеф участка можно назвать «холмисто-грядовым». Здесь на фоне мелкобугристой поверхности замытых старых отработок выделяются «холмы» размером до 250 м в плане и высотой до 5-7 м и узкие (5-15 м) вытянутые вдоль долины (30-220 м) «гряды» или валы высотой до 3 м. Эти положительные формы рельефа образованы отвалами мускульной бочковой отработки различными по составу. Отрицательные формы рельефа представлены замытыми карьерами, канавами, уступы и бровки которых частично сохранились. «Гряды» расположены, как правило, в отработанном пространстве и сложены крупными валунами - отвалами, складировавшимися, вероятно, рядом с бочкой по мере ее продвижения вдоль россыпи. «Холмы» представляют собой галевые и вскрышные отвалы. Основная часть отработанного пространства занята перебуторенным гале-эфельным материалом. Разрез участка мускульной отработки изучался траншеями 142 и 154. Собственно техногенные отложения представ-
Содержание золота в гале-эфельных образованиях возрастает сверху вниз от 13 до 448 мг/м³ , т.е. достигает промышленных значений в приплотиковом слое мощностью до 1 м (данные валового опробования). Увеличение концентрации золота в приплотиковой части с одновременным увеличением количества и крупности обломочного материала позволяет предполагать, что в техногенных отложениях участка мускульной отработки продолжается формирование золотоносного пласта до настоящего времени за счет перемыва их паводковыми водами и перемещения золота в низы разреза. Одновременно с техногенными образованиями промышленные содержания золота установлены в прибортовых целиках и породах плотика. Это позволило выделить и оконтурить на участке мускульной отработки промышленную техногенную россыпь.

Участок гидравлической отработки расположен выше мускульного полигона и протягивается на 1,5 км до устья руч. Теплого. Гидравлическая отработка по времени проведения является самой поздней, и поэтому ее площадь выделяется тем, что является «голой», лишенной леса и по- 
чвенного слоя. Техногенный рельеф участка типичен для россыпей, отработанных с применением гидромониторов и бульдозеров - вытянутый вдоль долины карьер с буграми бульдозерных отвалов, остатками запруд-накопителей воды и с водозаводными канавами по бортам. Разрез техногенных отложений изучен траншеей 166. Траншея вскрыла перебуторенные гале-эфельные образования, представленные валунно-галечным материалом с плитчатым щебнем алевролитов (породы плотика) и небольшим количеством песчано-супесного заполнителя $(20 \%)$. На гале-эфельные образования здесь наложены породы вскрыши и чисто эфельные отвалы. Усредненная общая мощность техногенных образований составила 2,3 м. Породы плотика, представленные рассланцованными алевролитами, вскрыты на глубину до 0,6 м. По данным валового опробования содержание золота в техноген-

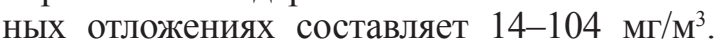
Наибольшие содержания отмечаются в приплотиковом слое, но и они не отвечают промышленным. Среднее содержание золота по траншее составило $59 \mathrm{Mг} / \mathrm{M}^{3}$ на массу, что ниже бортового $\left(100 \mathrm{M \Gamma} / \mathrm{M}^{3}\right)$.

Техногенная россыпь Проездной. Россыпь Проездной приурочена к ручьям Большой и Малый Проездной (рис. 2). Россыпь была открыта в 1932 г., в 1944 г. была произведена разведка россыпи, подсчитаны запасы россыпного золота. Поиски источников россыпей завершились открытием рудопроявления Проездное, в котором в трех кварцевых жилах с сульфидной минерализацией подсчитаны запасы до глубины 30 м в количестве 261,5 кг золота. Основная добыча велась в 19561968 гг. Кызылским разведочно-эксплуатационным предприятием (РЭП) [3]. Россыпь Мал. Проездной прослежена на 2,2 км при ширине от 10-15 до 60 м, мощность пласта 1 м, мощность торфов 3-4 м, содержание 300 мг/м³ массы. В пойме ручья Бол. Проездной россыпь прослежена на 0,8 км при ширине до 80-100 м. Мощность золотоносного пласта террасы достигает 1-4,5 м при мощности торфов от 10 до 99,5 м и содержании золота от 100-300 до 1000 мг/м³ массы. Золото месторождения крупное, слабоокатанное, с самородками. Нередки сростки с кварцем. За период эксплуатации добыто 372 кг золота. Обработанная россыпь Проездной разделяется в зависимости от применявшихся способов отработки на участки мускульной, гидравлической и гидромеханической отработки. Отвалы мускульной отработки открытым способом (15\% площади) возрастом
40-60 лет выделяются как невысокие отвалы, частично заросшие растительностью. Отвалы гидравлической отработки открытым способом (60\%) возрастом 25-30 лет выделяются в рельефе как отвалы высотой 3-5 м без следов растительности. Отвалы подземной отработки по руч. Мал. Проездной выделяются в виде невысоких отвалов высотой 1-2 м. Отвалы гидромеханической отработки открытым способом (современные) занимают небольшую площадь (15\%), высота их 3-7 м, лишены растительности.

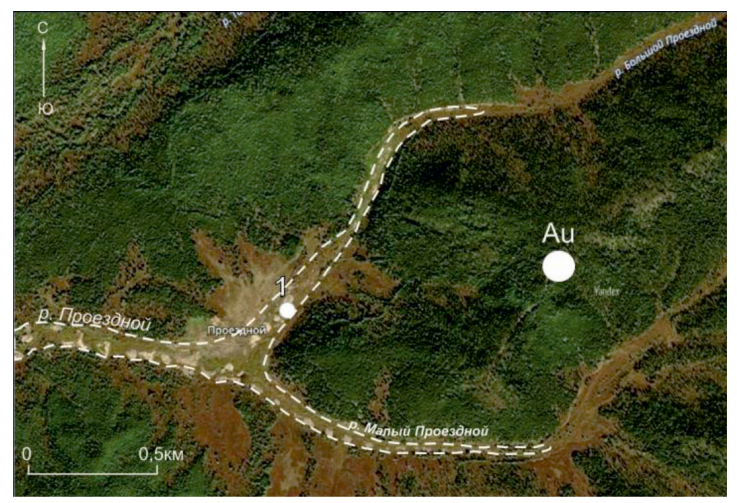

Рис. 2. Техногенньй отвальный комплекс отработанной россыпи Проездной

(1- точка отбора среднеобъемной пробы, Аи - рудное месторождение Проездное)

Оиенка ресурсов техногенного комплекса отложений отработанных россыпей Кара-Хем и Проездной. Прогнозная оценка ресурсов техногенного комплекса отложений (гале-эфельных отвалов) отработанной россыпи Кара-Хем проводилась с помощью бульдозерных траншей, из которых отбирались валовые посекционные пробы, промываемые на промприборе. Такой метод оценки оказался результативным и достоверным. Достоверность метода подтверждена проходкой заверочного разведочного полигона. Прогнозные ресурсы техногенных отложений россыпи Кара-Хем представлены в табл. 2. Промышленная техногенная россыпь золота выявлена на участке мускульной отработки прошлых лет. Усредненные параметры россыпи следующие: длина - 2900 м, ширина - 95 м, мощность торфов - 1,1 м, мощность песков - 1,5 м, объем песков - 374,4 тыс. м $^{3}$, содержание золота в песках - $376 \mathrm{mг} / \mathrm{M}^{3}$, прогнозные ресурсы золота - 140,8 кг. Россыпь является мелкой по запасам и относится к месторождениям 4-й группы сложности геологического строения по классификации ГКЗ. Среднее содержание золота по россыпям 
на участках дражной и гидравлической отработок ниже минимально промышленного содержания, поэтому эти россыпи можно отнести к забалансовым.

Прогнозные ресурсы техногенной россыпи Проездной авторами подсчитаны путем опытного опробования гале-эфельных отвалов. Главным видом опробования техногенного отвального комплекса являются среднеобъемные рядовые пробы объемом $0,2 \mathrm{M}^{3}$ (методические рекомендации [4]). Опробование производилось на точке 1 в долине руч. Бол. Проездной в 0,5 км выше его слияния с руч. Мал. Проездной (рис. 2). Содержание золота составило $87 \mathrm{mг} / \mathrm{m}^{3}$. Прогнозные ресурсы техногенных отложений россыпи Проездной составляют 11,5 кг и относятся к непромышленным (табл. 2).

Характеристика золота техногенных отложений. Золото из техногенных россыпей Кара-Хем и Проездной подвергалось ситовому анализу (табл. 3). В техногенной россыпи Кара-Хем преобладает крупное $(78,4 \%)$, слабоокатанное $(94,5 \%)$ золото комковатой $(80,7 \%)$ и уплощенной $(17,8 \%)$ формы. Пробность золота $860 \%$. В техногенной россыпи Проездной преобладает крупное и среднее золото $(80,8 \%)$, слабоокатанное, комковатой формы. Пробность золота $902 \%$.

\section{Заключение}

Техногенные отложения отработанных россыпей Кара-Хем и Проездной облада- ют высоким потенциалом для их повторной отработки. В долине р. Кара-Хем установлена промышленная техногенная россыпь золота на участке мускульной отработки и две непромышленные россыпи на участках дражной и гидравлической отработок. Прогнозные ресурсы золота в промышленной техногенной россыпи оцениваются в 140,8 кг при среднем содержании золота $376 \mathrm{мг} / \mathrm{M}^{3}$. Прогнозные ресурсы золота на участках дражной и гидравлической отработок оцениваются авторами в 65,9 кг. Прогнозные ресурсы техногенных отложений россыпи Проездной составляют 11,5 кг. В техногенных россыпях Кара-Хем и Проездной преобладает крупное золото, что гарантирует высокую извлекаемость при их отработке. Горно-геологические условия техногенных месторождений благоприятны для их отработки. Недопустимых экологических последствий освоение месторождений не вызовет, учитывая малую глинистость песков и многолетний опыт их эксплуатации предшественниками. Техногенные россыпи Кара-Хем и Проездной как с небольшими промышленными, так и с забалансовыми запасами могут отрабатываться малыми золотодобывающими предприятиями Тувы, непромышленные россыпи могут быть рекомендованы для рекреационной (туристической, любительской) россыпной золотодобычи в Туве по примеру Аляски [5].

Таблица 2

Выявленные опробованием прогнозные ресурсы техногенных отложений

\begin{tabular}{|c|c|c|c|c|}
\hline Тип россыпи & \begin{tabular}{|c|} 
Длина, \\
м
\end{tabular} & $\begin{array}{l}\text { Объем горной массы } \\
\text { техног. комплекса, } \text { м }^{3}\end{array}$ & $\begin{array}{l}\text { Содержание } \\
\text { золота, } \mathrm{мг} / \mathrm{M}^{3}\end{array}$ & $\begin{array}{l}\text { Ресурсы, } \\
\text { кг }\end{array}$ \\
\hline Кара-Хем, участок дражной отработки & 1300 & 283735 & 139 & 39,4 \\
\hline Кара-Хем, участок мускульной отработки & 2900 & 374468 & 376 & 140,8 \\
\hline Кара-Хем, участок гидравлической отработки & 1500 & 450000 & 59 & 26,5 \\
\hline Всего, Кара-Хем, техногенная & 5700 & & & 206,7 \\
\hline Проездной, техногенная & 3000 & 132857 & 87 & 11,5 \\
\hline
\end{tabular}

Таблица 3

Результаты ситового анализа

\begin{tabular}{|c|c|c|c|c|c|}
\hline \multirow{2}{*}{ Класс крупности } & Размер золотин, & \multicolumn{4}{|c|}{ Содержание класса } \\
\cline { 3 - 6 } & & \multicolumn{2}{|c|}{ россыпь Кара-Хем } & \multicolumn{2}{|c|}{ россыпь Проездной } \\
\cline { 3 - 5 } & & вес/\% & знак/\% & вес/\% & знак/\% \\
\hline Крупное & +1 & 78,4 & 0,78 & 55 & 6,5 \\
\hline Среднее & $-1+0,5$ & 12,6 & 1,43 & 25,8 & 25,8 \\
\hline Мелкое & $-0,5+0,25$ & 8,5 & 6,69 & 19,2 & 67,7 \\
\hline Весьма мелкое & $-0,25$ & 0,5 & 91,1 & - & - \\
\hline
\end{tabular}


Работа выполнена при финансовой поддержке проекта РФФИ № 17-45-170526.

\section{Список литературы / References}

1. Волков А.В. Золото Тывы от скифов до наших дней // Золото и технологии. 2011. № 1 (11) февраль [Электронный pecypc]. URL: http://zolteh.ru/regions/zoloto-tyvy-ot-skifovdo-nashih-dnej/ (дата обращения: 25.01.2019).

Volkov A.V. Gold Tyva from the Scythians to the present day // Zoloto i tekhnologii. № 1 (11)/fevral. 2011 [Electronic resource]. URL: http://zolteh.ru/regions/zoloto-tyvy-ot-skifovdo-nashih-dnej/ (date of access: 25.01.2019) (in Russian).

2. Прудников С.Г., Кононенко Н.Б., Петрова Л.И. Условия образования россыпей Тапса-Каахемской золотоносной зоны Тувы и их связь с коренными источниками // Геология и геофизика. 2011. Т. 52. № 2. С. 243-260.

Prudnikov S.G., Petrova L.I., Kononenko N.B., Formation conditions of placers in theTapsa-Kaakhem gold zone (Tuva) and their relation to primary sources // Russian geology and geophysics. 2011. V. 52. № 2. P. 193-207. DOI: 10.1016/j. rgg.2010.12.013.
3. Монгуш А.А. О добыче золота в Уранхайском крае // Новые исследования Тувы. 2014. № 3 [Электронный реcypc]. URL: https://www.tuva.asia/journal/issue_23/7325-mongush-aa.html (дата обращения: 25.01.2019).

Mongush A.A. About gold mining in the Uranhai region // Novyye issledovaniya Tuvy. 2014. № 3 [Elektronnyy resurs]. URL: https://www.tuva.asia/journal/issue_23/7325-mongushaa.html (date of access: 25.01.2019) (in Russian).

4. Куторгин В.И., Тарасов А.С., Головкин С.А. К методике разведки и оценки техногенного комплекса на россыпи платиноидов р. Кондёр // Золотодобыча. 2016. № 10 (215). C. 31-35.

Kutorgin V.I., Tarasov A.S., Golovkin S.A. To the method of exploration and assessment of the technogenic complex on the placers of platinum r. Conder // Zolotodobycha. 2016. № 10 (215). P. 31-35 (in Russian).

5. Верхозин C.C. Золотодобыча в Соединенных Штатах Америки. Разработка россыпей на Аляске // Золотодобыча. 2015. № 8 (201). C. 30-35.

Verkhozin S.S. Gold mining in the United States of America. Placer development in Alaska// Zolotodobycha. 2015. № 8 (201). P. 30-35 (in Russian). 